\title{
A ceifa da gripe espanhola entre os trabalhadores pobres e os miseráveis da Bahia (1918-1919)
}

\section{The spanish flu harvest among the poor workers and the miserable of Bahia (1918-1919)}

\section{Christiane Maria Cruz de Souza*}

Resumo: Este texto discorre sobre a epidemia de gripe espanhola em Salvador, capital da Bahia, Brasil. A pandemia que varreu o mundo entre 1918 e 1919 se disseminou na cidade a partir de setembro de 1918. Neste artigo objetiva-se analisar a disseminação da doença em diferentes distritos da cidade e se os efeitos da crise econômica e as condições materiais de existência da população interferiram no adoecimento e morte dos soteropolitanos, especialmente dos trabalhadores pobres e dos miseráveis. Esta reflexão se apoia em fontes primárias como jornais, artigos médicos publicados em periódicos especializados, relatórios de inspetores sanitários, livro de registro de óbitos, dentre outras.

Palavras-chave: epidemia; gripe espanhola; trabalhadores; pobres; Bahia.

Abstract: This text discusses the Spanish flu epidemic in Salvador, capital of Bahia, Brazil. The pandemic that swept the world between 1918 and 1919 spread in the city from September 1918. This article aims to analyze the spread of the disease in different districts of the city and whether the effects of the economic crisis and the material conditions of existence of the population interfered in the illness and death of the soteropolitanos, especially of the poor workers and of the miserable. This reflection is based on primary sources such as newspapers, medical articles published in specialized journals, reports by health inspectors, a death record book, among others.

Keywords: epidemic; Spanish flu; workers; poor; Bahia.

* Doutora em História das Ciências e da Saúde pela Casa de Oswaldo Cruz (Fiocruz). Membro do Núcleo de Tecnologia em Saúde do Instituto Federal de Educação, Ciência e Tecnologia da Bahia. ORCID: https://orcid.org/0000-0001-9716-7891. E-mail: chriscruz160@gmail.com. 
ste texto discorre, de forma breve, sobre a pandemia de gripe, doença respiratória aguda grave, provocada pelo vírus H1N1, que se espalhou pelo mundo entre 1918 e 1919, atingindo o Brasil em setembro de 1918. Não se tem, até hoje, um número preciso de adoecimentos e mortes provocados pela pandemia de gripe de 1918-1919, mas estima-se que a doença infectou um terço da população mundial, aproximadamente 500 milhões de pessoas, e vitimou cerca de 50 milhões. ${ }^{1}$ Neste artigo, contudo, não há a intenção de apresentar um estudo quantitativo da doença pandêmica, pretende-se analisar as condições que favoreceram a sua propagação na Bahia, Brasil, privilegiando a capital do estado, Salvador, na intenção de dar visibilidade a indivíduos e grupos socioeconômicos por ela atingidos, especialmente os trabalhadores e os denominados indigentes.

Doenças e epidemias fazem parte da experiência humana. A humanidade convive com agentes patogênicos desde os primórdios de sua vida no planeta. A necessidade de prover os próprios alimentos e, assim, assegurar sua sobrevivência, fez com que o homem interviesse no meio ambiente, desmatando para cultivar a terra, garantir pasto para os animais e assentar moradias. A derrubada das florestas, o convívio com animais de criação e domésticos, o armazenamento de grãos e o acúmulo de lixo favoreceram a proliferação de microrganismos como fungos tóxicos, bactérias e atraíram animais nocivos e insetos, portadores de vírus, bactérias e parasitas; favoreceram o surgimento de doenças como a malária, a peste, a febre amarela e zoonoses como a gripe, a tuberculose, a varíola, o sarampo, a catapora etc. A poluição das águas por dejetos resultou em poliomielite, cólera, febre tifoide, hepatite, coqueluche e difteria. ${ }^{2}$

Assuntos como esses permaneceram, por longo período, restritos aos domínios dos profissionais da área, especialmente dos médicos interessados em registrar a história da medicina e da sua profissão. A partir das últimas décadas do século XX, contudo, um número crescente de historiadores e cientistas sociais passaram a se interessar pelo assunto. Muitos se dedicaram a estudar as epidemias que afetaram as sociedades humanas ao longo da história. Apesar de ser um evento transitório, que se circunscreve em um curto espaço de tempo, a crise desencadeada por uma epidemia é dramática e revela as tramas do tecido social em que a doença irrompe de forma virulenta e letal. O interesse de historiadores e cientistas sociais por epidemias passadas não é, portanto, pelo evento biológico em si, mas porque este adquire significado e significação dentro de um contexto humano, nos diversos modos pelos quais se infiltra nas vidas das pessoas, nas interpretações que suscita, nas reações que provoca e respostas que exige; enfim, no modo pelo qual dá expressão a valores sociais, culturais e políticos.

1 TAUBENBERGER, Jeffery K.; MORENS, David M. 1918 Influenza: the Mother of All Pandemics. In: Emerging Infectious Diseases. A Peer-Reviewed Journal Tracking and Analyzing Disease Trends. v. 12, n. 1, jan. 2006. Disponível em: http://wwwnc.cdc.gov/eid/content/12/1/pdfs/v12-n1.pdf. Acesso em: 10 jun. 2013.

2 Mutações genéticas também podem provocar doenças e mortes. Cf.: PORTER, Roy. Das tripas coração. Rio de Janeiro: Record, 2004. 
Cada epidemia é única porque é causada por um microrganismo específico e incide em diferentes conjunturas e, portanto, provoca reações, interpretações e respostas diversas. Contudo, as epidemias não fogem a uma espécie de dramaturgia que, em linhas gerais, parece se repetir ao longo da história: uma doença surge misteriosamente em um determinado lugar e há um esforço para ignorá-la ou ocultá-la; a admissão de uma epidemia só acontece quando há um expressivo número doentes e mortos e se torna impossível negá-la; inicia-se, então, por pressão da sociedade, dos meios de comunicação ou até pelo crescente número de doentes e mortos, o processo de aceitação, de reconhecimento e posterior construção de uma base de conhecimentos para lidar com ela e administrar as medidas de saúde pública; a doença, por fim, declina e desaparece, quase tão misteriosamente quanto apareceu, podendo, por vezes, se tornar endêmica.

Esse processo é carregado de significados e tensões de todo tipo. É muito comum, por exemplo, o uso político da epidemia. As epidemias colocam em xeque a capacidade das autoridades públicas na gestão da crise, evidenciam os limites da ciência e da medicina e colocam em relevo as mazelas e fragilidades da sociedade. Em casos de doenças que se propagam de pessoa para pessoa, há, em geral, a eleição de culpados ou responsáveis por seu surgimento e disseminação. Autoridades públicas e sanitárias que não cumpriram seu dever, políticos de outros partidos ou meios de comunicação que querem a derrubada da economia e ver o governo fracassar são, comumente, culpabilizados sob a tensão da crise epidêmica em geral.

Na maioria das vezes, a origem da doença é associada a pessoas ou locais "sujos" e malcheirosos e essa percepção pode provocar reações xenofóbicas, a responsabilização dos "outros", os diferentes, pessoas de condição social, cultura, etnia, religião, nacionalidade, gênero etc., diversa da de quem os elege como culpados. Os "outros" servem de "bode expiatório" quando a doença se espalha, provocando muitas mortes. Contudo, os "outros", os diferentes, também elegem os seus alvos - um deus, que os pune por seus pecados ou as elites e/ou os políticos, que querem acabar com eles.

A doença mundialmente conhecida como gripe espanhola, na verdade, não se originou na Espanha. ${ }^{3}$ Este foi o país cuja imprensa denunciou, de imediato, a existência da epidemia de gripe porque não sofria censura semelhante à dos países que participavam da Primeira Guerra Mundial. ${ }^{4}$ A origem da pandemia, contudo, é motivo de controvérsia entre os estudiosos do assunto. Alguns defendem que a gripe surgiu simultaneamente na América do Norte, na Rússia e na China. ${ }^{5}$ Para Crosby, os primeiros registros da doença pandêmica apontam para os Estados Unidos - em março de 1918, mais de 1.000 operários da Ford Motor Company, em Detroit, e muitos soldados da base militar Camp Funston/Fort

3 A gripe era apelidada na Espanha por "La dançarina". Cf.: A “INFLUENZA hespanhola" - Vítimas brasileiras. Diário de Notícias, Salvador, p. 1, 23 set. 1918.

4 A Espanha não participou da Primeira Guerra.

5 Cf.: PHILLIPS, Howard; KILLINGRAY, David (ed.). The spanish influenza pandemic of 1918-19: new perspectives. London; New York: Routledge, 2003. p. 5. 
Riley, no Kansas, foram hospitalizados, apresentando sintomas semelhantes aos da gripe pandêmica. ${ }^{6}$

Logo quando surgiu, a doença se mostrou benigna na maioria dos casos: a cura era alcançada depois de três ou quatro dias da manifestação dos primeiros sinais. Contudo, apesar da benignidade observada naquele primeiro surto, a gripe logo se espalhou por outros campos de treinamento do Exército dos EUA, viajando para a Europa a bordo dos navios que levaram as tropas que participariam do conflito bélico em curso. A sua disseminação foi favorecida pela aglomeração e movimentação de milhões de homens em campos de treinamento militar e trincheiras durante a Primeira Guerra Mundial. A epidemia, contudo, não se limitou ao cenário da guerra, extrapolou as fronteiras dos países envolvidos no conflito, se espalhou por toda a Europa, chegando, rapidamente, a outros continentes, em um mundo interconectado por pessoas em viagens de negócios e de lazer. ${ }^{7}$

É difícil precisar o momento da entrada da "espanhola" em Salvador, cidade portuária, com conexões regionais, nacionais e internacionais desde a sua fundação. ${ }^{8}$ Por causa dessa característica, a baía de Todos-os-Santos era definida pelos médicos como o portal de entrada das mais exóticas enfermidades. ${ }^{9}$ Esse argumento, utilizado por muitas autoridades sanitárias da Bahia nas primeiras duas décadas do século XX, objetivava, sobretudo, atribuir à União, a quem cabia administrar a Saúde do Porto, a responsabilidade pela entrada e disseminação de doenças transmissíveis no estado.

Periodicamente a gripe fazia sua visita a esse porto sem que o fato provocasse grandes transtornos à rotina da cidade. ${ }^{10}$ Até setembro de 1918, a imprensa local repercutia as notícias sobre a epidemia em curso na Europa, assim como sobre a infecção dos militares brasileiros envolvidos nas operações da Primeira Guerra - os integrantes das missões médico-militares Frontin e Nabuco Gouveia foram infectados pela gripe espanhola assim que os navios atracaram em portos africanos. ${ }^{11}$ Apesar de consternados com as notícias do adoecimento e mortes de europeus e dos militares brasileiros antes

6 CROSBY, Alfred W. America's forgotten pandemic: the influenza of 1918. 2nd ed. New York: Cambridge University Press, 2003. p. 18-19.

7 Para saber mais sobre o assunto, consulte: BEVERIDGE, W.I.B. Influenza: the last great plague: an unfinished story of discovery. New York: Prodist, 1977; CROSBY, Alfred W. America's forgotten pandemic: the influenza of 1918. 2nd ed. New York: Cambridge University Press, 2003; PORRAS-GALLO, María-Isabel. Um reto para la sociedad madrilena: la epidemia de gripe de 1918-19. Madrid: Editorial Complutense, 1997.

8 A importância que o porto de Salvador assumiu desde a montagem da colônia portuguesa perdurou durante todo o século XIX até o início do século XX. Cf.: MATTOSO, Kátia M. de Queirós. Bahia: a cidade de Salvador e seu mercado no século XIX. São Paulo: Hucitec, 1978.

9 Cf.: MESQUITA, Lydio de. A defesa sanitária da Bahia contra a cholera-morbo. Gazeta Médica da Bahia, Salvador, n. 50, p. 375-389, 1919.

10 A exceção da pandemia que atingiu a Bahia em janeiro de 1890, trazida por um navio procedente de Hamburgo, na Alemanha. Extremamente contagiosa, a doença rapidamente se disseminou, atingindo os integrantes da colônia alemã, os empregados do setor de serviços, os operários das fábricas e corporações diversas. Embora benignos em sua maioria, os casos tornaram-se muito numerosos, chegando a atingir quase metade da população. Cf.: RODRIGUES, Raimundo Nina. A epidemia de influenza na Bahia em 1890. Gazeta Médica da Bahia, Salvador, n. 22, p. 548-557, p. 550-556, 1891.

11 Os integrantes dessas missões foram acometidos e vitimados pela gripe após atracarem em Freetown, Serra Leoa e em Dakar, no Senegal, antes mesmo que participassem das operações de combate das forças aliadas. Cf.: A “INFLUENZA hespanhola" - Vítimas brasileiras. Diário de Notícias, Salvador, p. 1, 23 set. 1918. 
mesmo que participassem da guerra, os baianos acreditavam que a doença não atingiria o Brasil.

Ledo engano! Na última quinzena de setembro daquele ano, a imprensa local começou a noticiar óbitos por gripe na cidade, relacionando-os à chegada do navio inglês Demerara em Salvador, no dia 11 daquele mês. ${ }^{12}$ Reportagem publicada no Diário de Notícias informava que havia passageiros infectados a bordo e ocorrera cinco óbitos na embarcação. Duas pessoas que desembarcaram em Salvador morreram depois de contrair a doença. O primeiro óbito, de "uma moça", ocorreu no dia seguinte ao de sua chegada, antes mesmo que ela pudesse ser hospitalizada. Dois dias depois do desembarque, morreu um outro passageiro no hospital da Santa Casa. ${ }^{13}$ No final de setembro, a gripe já se propagava com extrema virulência, impressionando a todos pelo elevado número de casos.

\section{Dançando no ritmo da "espanhola"}

QUANDO A PRESENÇA DA EPIDEMIA de gripe em Salvador foi denunciada pela imprensa, as autoridades públicas apressaram-se a negar o fato ou a minimizar-lhe os riscos. Predominava entre os médicos e autoridades sanitárias o sentimento de familiaridade em relação à doença e a crença em seu caráter de benignidade. A gripe ou influenza não era uma doença estranha aos baianos. Visitava a cidade com uma certa periodicidade. Aparecia na estação mais fria, acometia um certo número de pessoas e, no espaço de uma semana, sumia sem provocar consequências muito desastrosas: não furtava muitos braços ao trabalho, não provocava a paralisia das atividades produtivas, não desabastecia a cidade, não afastava os visitantes, comerciantes e investidores estrangeiros, nem era a causa de uma descendência doentia.

Desde a epidemia de 1890 que os números de óbitos causados pela gripe eram insignificantes diante da taxa de mortalidade de males como a disenteria, a peste, a varíola, a febre amarela e, sobretudo, a malária e a tuberculose. O fato de a gripe não ser doença de notificação compulsória não contribuía para a percepção do caráter epidêmico que a doença assumia naquela altura. ${ }^{14}$

Os médicos e autoridades sanitárias estavam mais preocupados com a possibilidade de eclosão e disseminação do cólera, devido à guerra em curso na Europa. ${ }^{15}$ Histórias do passado podem moldar as percepções do presente. Assim, o que pode tornar uma doença mais ou menos temida que outras é a memória que evoca. ${ }^{16} \mathrm{~A}$ memória dos sucessivos surtos

12 A INFLUENZA espanhola espalha-se em nossos navios. O Imparcial, Salvador, p. 1, 24 set. 1918; UMA nova epidemia está assolando a capital. Influenza? Gripe Espanhola? A Tarde, Salvador, p. 1, 25 set. 1918.

13 Cf.: DOS INFLUENZADOS do "Demerara", dois vieram a falecer já nesta capital. Diário de Notícias, Salvador, p. 1,2 out. 1918.

14 Cf.: SOUZA, Christiane M. ${ }^{a}$ Cruz de. A gripe espanhola na Bahia: saúde, política e medicina em tempos de epidemia. Rio de Janeiro: Editora Fiocruz; Salvador: Edufba, 2009.

15 MESQUITA, op. cit., 1919, p. 375-389.

16 RANGER, Terence; SLACK, Paul. Epidemics and ideas: essays on the historical perception of pestilence. Cambridge; New York: Cambridge University Press, 1992. p. 8-9. 
de gripe que irromperam no estado não era tão aterradora quanto a suscitada pela lembrança terrível da epidemia de cólera de 1855, cujos efeitos negativos provocaram transformações importantes naquela sociedade. ${ }^{17}$ Ao serem indagadas sobre a possibilidade de nova epidemia de cólera, as autoridades médicas demonstravam apreensão em grau muito superior à que deixavam transparecer em relação à epidemia de gripe em curso.

Já os políticos cuidavam de evitar possíveis prejuízos causados pela febre amarela. ${ }^{18}$ Apesar do baixo número de casos apresentados na ocasião, a incidência periódica da febre amarela conferia ao porto da Bahia a fama de "porto sujo", o que dificultava os negócios com estrangeiros em um estado cuja base da economia era o comércio de exportação de bens primários. ${ }^{19}$ Medidas clássicas de controle e profilaxia das doenças transmissíveis recomendadas por médicos e autoridades sanitárias - restrição do contato e da livre circulação de pessoas, proibição de eventos e interdição de lugares públicos, vigilância domiciliária e portuária, quarentena dos navios, isolamento dos doentes - e os efeitos dessas restrições na economia, via de regra desagradavam ricos e pobres. Ao longo da história, essas medidas provocaram revoltas e resistência da população, por seu caráter autoritário, restritivo da liberdade individual, da interferência na vida privada, por ir de encontro a crenças, costumes e valores arraigados na população, como também por desconhecimento e medo dos efeitos e consequências das medidas preconizadas.

Além dos fatores apontados acima, as incertezas acerca da natureza da doença e a necessidade de se estabelecer o diagnóstico para a adoção de medidas profiláticas e terapêuticas eficazes contribuíam para postergar a tomada de decisões. Matérias veiculadas pelos jornais da Bahia repercutiam a perplexidade dos médicos diante da gravidade que a gripe apresentava naquela quadra. A variabilidade dos sintomas apresentados, a aparente falta de imunidade dos supostamente curados, a faixa etária incomum dos acometidos e vítimas da doença - jovens -, bem como a situação de calamidade que se configurou, quase que simultaneamente, em diferentes lugares do mundo, fez com que os médicos suspeitassem que não se tratava da gripe benigna que estavam acostumados a tratar e sim de uma doença nova.

Médicos e cientistas europeus, que vinham lidando diretamente com os casos epidêmicos, emitiam explicações diversas sobre a doença e sobre as suas causas. Estavase na vigência da bacteriologia, da pesquisa de laboratório e cientistas do mundo todo se debruçaram sobre seus microscópios e lâminas de cultura na tentativa de descobrir o micróbio da doença. Consultados pela imprensa, os médicos baianos eram cautelosos ao emitirem uma opinião, apesar de a maioria se posicionar a favor do diagnóstico de gripe, com a qual já estavam familiarizados. Ao transbordar para as páginas dos jornais, essa falta

17 DAVID, Onildo Reis. O inimigo invisivel: epidemia na Bahia no século XIX. Salvador: Edufba, 1996.

18 Nesse período, a varíola e a febre amarela recebiam atenção especial dos governos federal e estadual, ainda que se mostrassem incipientes as medidas profiláticas e os recursos a estas destinados. Cf.: SOUZA, op. cit.

19 A INFLUENZA na Bahia é... política! O porto sujo. O Imparcial, Salvador, p. 1, 28 set. 1918. 
de homogeneidade a respeito da etiologia da doença causava perplexidade e apreensão na sociedade. ${ }^{20}$

Informado das controvérsias em torno da etiologia da doença, o diretor-geral da Saúde Pública da Bahia (DGSPB) resolveu nomear uma comissão de médicos para estudar a epidemia, estabelecer o diagnóstico, um prognóstico e a profilaxia adequados. Para ele, era preciso determinar primeiro se em Salvador grassava a gripe, identificada como doença benigna e sazonal, ou se o mal que invadira a cidade era o mesmo que assolava o cenário da Primeira Guerra Mundial. Tal conhecimento nortearia as ações daquele órgão do governo estadual no combate à epidemia.

Os médicos escolhidos para compor a comissão - Frederico Koch, Dyonisio Pereira e Aristides Novis - eram representantes da elite médica estadual, profissionais com grande credibilidade não só entre seus pares como em toda a sociedade baiana. Além de integrarem o quadro da Inspetoria Sanitária, repartição subordinada à Diretoria Geral da Saúde Pública da Bahia, clinicavam na cidade e exerciam a atividade de professores da Faculdade de Medicina da Bahia. ${ }^{21} \mathrm{~A}$ comissão examinou um número superior a 500 doentes distribuídos em quartéis e enfermarias do Exército, na Brigada Policial, na Guarda Civil, no Colégio dos Órfãos de S. Joaquim, na Guardamoria da Alfandega Federal, na Escola de Aprendizes Marinheiros, no Hospital Militar, chegando à conclusão de que não se tratava de nenhuma doença nova, mas sim de gripe ou influenza, periodicamente observada na Bahia. ${ }^{22}$

Não havia remédio específico para a gripe, a medicina oferecia alívio para os sintomas. Não havia tempo hábil para se produzir uma vacina respeitando-se os protocolos exigidos pela ciência. Os médicos sabiam que um indivíduo infectado se tornava um agente disseminador da doença - ao falar, tossir ou espirrar, o doente expelia em seu ambiente esputos ou perdigotos contaminados, que contagiavam os que se encontravam nas proximidades. Assim, recomendavam a adoção de hábitos de higiene para evitar a infecção, como a lavagem contínua das mãos e do rosto, das fossas nasais, da garganta e medidas que evitassem a transmissão de um indivíduo para outro - vigilância domiciliária e portuária, quarentena dos navios, isolamento dos doentes, restrição do contato próximo entre os indivíduos, interdição de eventos e locais que favorecessem a aglomeração, desinfecção dos lugares públicos e de diversas coletividades.

Cientes de que a aglomeração de pessoas contribuía para o aumento do contágio e da capacidade de propagação da gripe, a comissão concluiu que a doença se disseminava

20 Cf. SOUZA, Christiane Maria Cruz de. A epidemia de gripe espanhola: um desafio à medicina baiana. História, Ciências, Saúde - Manguinhos, Rio de Janeiro, v. 15, n. 4, p. 945-972, dez. 2008. Disponível em: http://www.scielo.br/scielo.php?script=sci arttext\&pid=S0104-59702008000400004\&lng=en\&nrm=iso. Acesso em: 8 jun. 2020.

21 Frederico Koch era inspetor sanitário do $15^{\circ}$ distrito e professor da Faculdade de Medicina da Bahia, ocupando a cadeira de farmacologia e arte de formular, no período de 1917 a 1919; Aristides Novis lecionou na mesma instituição e, no ano de 1919, ocupou a cadeira de fisiologia, atuando também como inspetor sanitário do $7^{\circ}$ distrito; Dyonisio Pereira também exerceu a função de inspetor sanitário do $4^{\circ}$ distrito. Para saber mais, ver Eduardo de Sá Oliveira em Memória histórica da Faculdade de Medicina da Bahia, concernente ao ano de 1942.

22 PELA Saúde Pública. O Democrata, Salvador, p. 1, 4 out. 1918. 
em velocidade tão acelerada naquela quadra e com um raio de ação tão abrangente em Salvador, devido à "superlotação de várias habitações coletivas, por isso constituídas em núcleos evidentes de irradiação epidêmica". ${ }^{23}$ Para o médico, cientista e professor da Faculdade de Medicina da Bahia, Gonçalo Moniz, a aglomeração era a mais anti-higiênica de todas as condições de uma habitação, já que favorecia a promiscuidade, o contato íntimo dos indivíduos. ${ }^{24}$ Gonçalo Moniz argumentava que os "germens" tinham sobrevida breve fora de um organismo vivo. Para ele, os principais focos dos patógenos causadores de doenças infecciosas, "os habitats e meios naturais de cultura desses microrganismos, são os próprios homens, os doentes, os convalescentes ou portadores sãos de tais seres animados". Portanto, concluía que havendo em um domicílio uma pessoa acometida por uma doença contagiosa, ela, facilmente, contaminaria outras e esse número seria maior quanto maior fosse a promiscuidade nas moradias. ${ }^{25}$

A questão é que, naquela altura, Salvador atravessava uma crise no setor imobiliário, agravada pela transformação dos prédios residenciais do centro da cidade em estabelecimentos comerciais, como também pela demolição dos velhos casarões e o desalojamento de significativo número de pessoas pobres que ali habitavam, sem que o estado ou o município Ihes oferecessem alternativa de moradia. ${ }^{26}$ Havia grande carência de imóveis para alugar e alguns grupos - comerciantes, companhias industriais, ordens religiosas, sociedades filantrópicas etc. - monopolizavam o setor, o que favorecia a especulação imobiliária. ${ }^{27}$

Em face da carestia dos gêneros de primeira necessidade, dos altos preços dos aluguéis, dos baixos salários e das deficiências do sistema de transporte, os trabalhadores procuravam morar próximos às fábricas ou ao centro administrativo e comercial da cidade para evitar a distância e os altos custos do deslocamento até o local de trabalho. As famílias se aglomeravam em "avenidas", ${ }^{28}$ cortiços, vilas operárias e em sobrados subdivididos em cubículos arruinados, sem ventilação, úmidos, escuros, sem instalações sanitárias apropriadas, situados em ruas repletas de lixo, sem redes de esgoto e água encanada. Todas essas modalidades de moradia eram extremamente precárias e favoreciam a propagação

$23 \mathrm{KOCH}$, Frederico; PEREIRA, Dionísio; NOVIS, Aristides. A epidemia de gripe. Parecer da comissão nomeada pelo Diretor da Saúde Pública da Bahia. Gazeta Médica da Bahia, Salvador, n. 50, p. 151-153, 1918.

24 MONIZ, Gonçalo. Relatório. Bahia: Imprensa Oficial do Estado, 1921. p. 371.

25 Idem, ibidem.

26 Cf.: CARDOSO, Luiz Antonio F. Entre vilas e avenidas: habitação proletária em Salvador, na Primeira República. 1991. Dissertação (Mestrado em Arquitetura e Urbanismo) - Faculdade de Arquitetura, Universidade Federal da Bahia, Salvador, 1991; PINHEIRO, Eloísa Petti. Europa, França e Bahia: difusão e adaptação de modelos urbanos (Paris, Rio e Salvador). Salvador: Edufba, 2002; SANTOS, Mário Augusto Silva. Crescimento urbano e habitação em Salvador (1890-1940). RUA Revista de Arquitetura e Urbanismo, Salvador: Faculdade de Arquitetura da UFBA, v. 3, n. 4/5, p. 20-29, 1990.

27 CASTELLUCCI, Aldrin A. S. Salvador dos operários: uma história da greve geral de 1919 na Bahia. 2001. Dissertação (Mestrado em História) - Faculdade de Filosofia e Ciências Humanas, Universidade Federal da Bahia, Salvador, 2001. p. 40-54; SANTOS, op. cit., p. 26.

28 Casas geminadas, com apenas uma porta ou porta e janela, separadas por paredes que serviam de divisórias entre elas. 
de doenças devido, principalmente, à promiscuidade em que eram obrigados a viver os seus habitantes. ${ }^{29}$

Conforme ressaltavam os médicos, esse cenário era favorável à propagação da gripe. Reportagem publicada no jornal O Imparcial ressaltava que "a cidade inteira" estava "transformada num hospital" e "a angústia e luto" se estendiam "por todo o seio da população", mas se todas as classes sofriam as consequências funestas da doença, era entre as camadas mais pobres da população que elas eram mais cruéis. Diante da falta de recursos pecuniários, restava aos pobres a alternativa de assistir "à corrente dos estragos nos seus lares, que se despovoam[despovoavam], varridos pela fatalidade, sem assistência médica e sem um socorro de um medicamento sequer". ${ }^{30}$

Nesse período havia enorme contingente de desempregados. A oferta de mão de obra era superior à capacidade de absorção pelos setores industrial e de serviços. Poder prover a própria sobrevivência era o maior desafio do soteropolitano naquela altura. Muitos se submetiam a viver de biscates, buscando o seu sustento por meio de algum tipo de trabalho temporário. Outros recorriam à mendicância. Matéria publicada no jornal $A$ Tarde denunciava que estes eram os alvos preferenciais da "espanhola". Segundo o articulista, diariamente, dezenas de pessoas eram vitimadas, sorrateiramente, pela doença, sem que lhes fosse oferecido qualquer socorro público. O quadro descrito era tenebroso:

As portas das igrejas, dos teatros e os bancos dos passeios públicos estão empilhados de indigentes prostrados pela fome e pelas trágicas manifestações da moléstia impiedosa.

É de sensibilizar o mais frio coração vê-los ao desamparo, estendidos nas calçadas, fitando ao longo o céu com os olhos embaciados de agonizantes, onde chora a última lágrima e morre a esperança derradeira. ${ }^{31}$

Eram dos desempregados e trabalhadores pobres e suas famílias os cadáveres que eram enviados pelas autoridades policiais para o Instituto Médico Legal Nina Rodrigues. As fontes não explicitam se esses que morriam ao abandono eram contabilizados pela estatística oficial. Inferimos que os corpos recolhidos nas ruas e enviados para a "morgue" 32 eram aqueles computados como de profissão ignorada. Todavia, caso a DGSPB não tomasse conhecimento dessas mortes, os jornais faziam questão de denunciá-las:

[...] só este mês já foram inumados no cemitério das Quintas dos Lázaros, saídos da "morgue", 168 indigentes.

Os carros para transporte de cadáveres não são suficientes e por isso a toda hora se dá com o triste espetáculo de ver passar pelas ruas, sobre uma tábua

29 Os relatórios dos inspetores sanitários descrevem bem esse cenário. Cf.: NOVIS, Aristides. Relatório das principais ocorrências do $5^{\circ}$ Distrito de Saúde Pública, no $2^{\circ}$ semestre do ano de 1912 , apresentado pelo inspetor dr. Aristides Novis, caixa: 3696, maço: 1028, 1912; ROCHA, Álvaro F. Relatório apresentado pelo Dr. Álvaro da Franca Rocha, inspetor sanitário do $9^{\circ}$ Distrito. $2^{\circ}$ semestre de 1912, caixa: 3696, maço: 1028, 1913.

30 SOCORREI o povo! Sob o peso da gripe e sem elementos para defender-se. O Imparcial, Salvador, p. 1, 23 nov. 1918.

31 NÃO haja ilusões. Não nos devemos, entretanto, iludir. A Tarde, Salvador, p. 1, 26 out. 1918.

32 Como era chamado o IML. 
apenas, amarrados com cordas e arames, os mortos, coletados nos passeios e nas praças públicas, a caminho da "morgue". ${ }^{33}$

Os jornais listavam os mortos, publicando o nome e endereço das vítimas da doença. De alguns se desconhecia o sobrenome, registrava-se "de tal" ou simplesmente o suprimia, e o local onde o corpo foi recolhido: "Minerva de tal", ao Pilar; "Alice de tal", em São Caetano; Abrahão, à Cidade de Palha; "João de tal", do Pilar; Maria do Carmo, do S. Caetano; "José de tal", de São Caetano. ${ }^{34}$ Os locais registrados pelos jornais remetiam a bairros reconhecidamente pobres e/ou periféricos na época: Cabula, São Caetano, Pilar, Penha, Lapinha, Amaralina, Pernambués, Bonfim, Brotas, Fazenda Grande, São Cristóvao, Ladeira da Conceição, Ladeira da Preguiça, Cruz do Cosme, Baixa dos Sapateiros, Estrada das Boiadas, Cais do Ouro, Cidade de Palha, Rua do Tijolo, Rua do Oriente, Rua do Silva, eram os sítios citados com maior frequência.

O distrito de Santo Antônio Além do Carmo, que abrangia os atuais bairros do Barbalho, da Baixa de Quintas, Lapinha, Liberdade, São Caetano, Fazenda Grande e imediações, era o que apresentava o maior número de óbitos - $55 \%$ dos mortos por gripe espanhola de Salvador eram provenientes desse distrito. ${ }^{35}$ Do ponto de vista imobiliário, Santo Antônio aparecia como uma das áreas mais desvalorizadas de Salvador - $74 \%$ dos seus habitantes não possuíam casa própria, viviam em casas de cômodos ou "correr de casas" conjugadas, onde ocupavam apenas um quarto e não contavam com instalações sanitárias próprias. ${ }^{36}$

Além da vasta área, o distrito do Santo Antônio Além do Carmo possuía ocupação heterogênea, cujas características variavam da grande concentração urbana a terrenos de aspecto rural. No largo do Queimado, no atual bairro da Caixa D’Água, havia uma pequena vila operária onde moravam cerca 90 empregados da Fábrica Santo Antônio do Queimado, pertencente à Companhia União Fabril da Bahia. Nas imediações, no largo do Barbalho, estava instalada a fábrica de calçados Stella, cujos 100 operários, provavelmente, moravam nas proximidades desse estabelecimento industrial. Na Liberdade e São Caetano instalaram-se grande parte dos libertos da escravidão e, no início do século XX, os desalojados pela reforma urbana promovida por J. J. Seabra. ${ }^{37}$

Conforme se pode observar, variada também era a conformação social daquele distrito. Ali habitavam desde elementos das camadas médias, tais como profissionais liberais e funcionários públicos, até os segmentos mais empobrecidos da população - empregados dos estabelecimentos comerciais e das companhias dos serviços urbanos, operários de fábricas e oficinas de Salvador, além daqueles que viviam do mercado informal de trabalho.

33 OS CADÁVERES entrados na "morgue" nas últimas 48 horas. A Tarde, Salvador, p. 2, 31 out. 1918.

34 São muitos os nomes listados, foram escolhidos os que podiam ilustrar a afirmação. Para saber mais, confira: A GRIPPE prossegue na sua derrocada. Mais casos fatais. Entraram, ontem, nesse porto, 9 vapores, 7 conduzindo pestosos. O Imparcial, Salvador, p. 1, 16 out. 1918.

35 DIRECTORIA Geral de Saúde Pública da Bahia. Serviço de Estatística Demografo-Sanitária. O Democrata, Salvador, p. 2, 10 nov. 1918.

36 Um cubículo nos fundos do terreno servia a todas as casas.

37 Para saber mais sobre a reforma urbana promovida por Seabra, veja: PINHEIRO, op. cit. 
Os funcionários das repartições públicas - correios, companhias de gás e eletricidade foram fortemente atingidos pela gripe $-76 \%$ adoeceram. Nos Correios, a contaminação atingiu mais de $86 \%$ do efetivo, ao ponto de a distribuição da correspondência ficar seriamente prejudicada. ${ }^{38} \mathrm{O}$ trabalho confinado em espaços exíguos, contato próximo entre os colegas de trabalho e destes com o público, a manipulação de material infectado eram fatores que contribuíam para que esses trabalhadores fossem mais facilmente contaminados com a doença.

Naquela altura, a situação do funcionalismo público não era melhor que a dos demais trabalhadores. Os baixos e incertos salários e as difíceis condições de vida dos indivíduos que compunham o estrato inferior da camada média, composta por professores de escolas públicas, empregados de repartições públicas, telefonistas etc., os aproximavam da camada mais pobre da sociedade, ainda que os primeiros se considerassem superiores a esses últimos. A par da compressão salarial - não recebiam reajustes desde 1896 - e dos atrasos no pagamento dos seus vencimentos, essa categoria lidava com a questão da instabilidade no emprego. Como não era comum a realização de concursos públicos para o preenchimento das vagas, o candidato a funcionário dependia de indicação política. Nomeado, a sua condição de dependência aumentava - o valor dos seus vencimentos variava conforme o grau de proximidade com os altos escalões do poder, arriscando-se a ser rebaixado de função ou demitido durante as mudanças de governo. ${ }^{39}$

Além dos problemas em comum com outras categorias do funcionalismo público, os professores primários municipais enfrentavam outras dificuldades para exercer sua atividade profissional. Nesse período, o aluguel dos imóveis, onde funcionavam as escolas, era de responsabilidade dos próprios professores, que, para tanto, contavam com um pequeno acréscimo em seus salários. Todavia, os atrasos constantes dos seus vencimentos transformavam o professor em "devedor crônico" ou o obrigava a arcar sozinho com essa despesa. ${ }^{40}$ Apesar de o serviço de estatística não especificar o número de professores doentes, a imprensa informava que muitos foram infectados pela gripe, alguns gravemente. Entre 20 e 26 de outubro de 1918, 93,34\% do efetivo da Escola Pública da Rua do Mota contraiu a gripe; na Escola Pública da Boa Vista foram 88,24\%; na Escola Pública do Jogo do Lourenço 77,78\% adoeceu de gripe; na Escola Pública do Corredor da Lapinha $77 \%$ se infectou. O grande número de gripados nas instituições de ensino levou a DGSPB a ordenar o fechamento das escolas. Ao todo, mais de $45 \%$ do efetivo das escolas públicas contraiu a doença, enquanto que $36 \%$ dos que integravam os colégios e escolas privadas adoeceram. No cômputo geral das escolas e colégios públicos e privados, onde o tempo de permanência e de exposição à contaminação era menor que o requerido nas fábricas, o número de gripados

$\overline{38}$ DIRECTORIA Geral de Saúde Pública da Bahia. O Democrata, Salvador, p. 2, 6 nov. 1918.

39 SAMPAIO, Consuelo Novais. Os partidos políticos da Bahia na Primeira República - uma política de acomodação. Salvador: Edufba,1999.

40 CASTELLUCCI, op. cit., p. 46-47; SANTOS, op. cit., p. 53-64. 
foi inferior, mas ainda assim bastante alto $-38,58 \%$ da comunidade escolar foi atingida pela gripe. ${ }^{41}$

Tal como o Santo Antônio Além do Carmo, Brotas era um distrito de grande extensão, igualmente heterogêneo e foi o segundo em número de mortes - $33 \%$ dos óbitos por gripe. ${ }^{42}$ Pertenciam a Brotas os atuais bairros do Matatu, Engenho Velho de Brotas, Cabula, Pernambués, Rio Vermelho, Amaralina e Pituba. ${ }^{43}$ Com tão vasto território, é natural que o distrito apresentasse realidades geográficas e socioeconômicas diversas - havia desde zonas urbanizadas a localidades com características quase rurais, onde proliferavam hortas, roças e chácaras cuja produção agropastoril era voltada para o abastecimento do mercado de Salvador. ${ }^{44}$ Nos terrenos situados na orla marítima - Pituba, Amaralina e Rio Vermelho -, transformados em balneários pela burguesia soteropolitana, casas de veraneio conviviam com as tradicionais comunidades de pescadores, especialmente, no Rio Vermelho. Nos limites do Rio Vermelho com o distrito de Brotas, concentravam-se os trabalhadores pobres das fábricas e oficinas instaladas na Cidade Alta. ${ }^{45}$

O número de pescadores e lavradores infectados e mortos por gripe era irrisório se comparado às outras categorias de trabalhadores. Estas eram atividades realizadas ao ar livre e não exigia, de modo geral, proximidade com outras pessoas que exerciam o mesmo ofício. O alto número de adoecimentos e mortes atribuídos ao distrito se devia, certamente, aos operários que ali habitavam.

Não se pode esquecer, também, que nas Pitangueiras erguia-se o Hospital Militar, onde eram internados os enfermos pertencentes às corporações militares. Matéria publicada no jornal O Imparcial em 26 de outubro de 1918 informava que naquela quinzena os quartéis haviam se esvaziado, dado o grande número de doentes e que o Hospital Militar já não tinha leitos para receber os doentes que ali chegavam. Para acomodar os 234 militares doentes que já se encontravam internados, os enfermeiros improvisaram leitos no chão e pelos corredores. ${ }^{46}$

Ocupando o terceiro lugar nessa classificação funesta, o distrito de Nazaré registrou, aproximadamente, $27 \%$ dos óbitos. ${ }^{47}$ Esse distrito também não apresentava ocupação uniforme - a relativa proximidade com o centro comercial e administrativo da cidade fazia com que ali se instalassem os trabalhadores com função no setor de serviços públicos e privados, operários de fábricas e oficinas, assim como os que viviam na informalidade. ${ }^{48} \mathrm{O}$ distrito compreendia, além do próprio território, os atuais bairros da Saúde e do Tororó, em cujas

41 DIRECTORIA Geral de Saúde Pública da Bahia. O Democrata, Salvador, p. 2, 6 nov.1918.

42 Cf.: DIRECTORIA Geral de Saúde Pública da Bahia. Serviço de Estatística Demografo-Sanitára. O Democrata, Salvador, p. 2, 10 nov. 1918

43 A ocupação da Pituba ocorreu de forma organizada, mediante um grande loteamento projetado por Theodoro Sampaio em 1919. Cf.: CARDOSO, op. cit., p. 125.

44 CARDOSO, op. cit., p. 140; PINHEIRO, op. cit., p. 127-194.

45 CARDOSO, op. cit., p. 140.

46 O ESTADO sanitário da Bahia é impressionador. O Imparcial, Salvador, p. 1, 26 out. 1918.

47 DIRECTORIA Geral de Saúde Pública da Bahia. Serviço de Estatística Demografo-Sanitária. O Democrata, p. 2, 10 nov. 1918.

48 PINHEIRO, op. cit., p. 257. 
ladeiras, becos e vielas $85 \%$ dos moradores eram pobres de casas de cômodo, "avenidas" e vilas. ${ }^{49} \mathrm{Na}$ atual rua Djalma Dutra, região da Fonte Nova, estavam situadas a fábrica de tecidos São Salvador e a respectiva vila operária, com 54 casas. ${ }^{50}$

Em Nazaré também funcionava o Hospital Santa Izabel, da Santa Casa da Misericórdia da Bahia. Durante a epidemia, o Santa Izabel reabriu uma enfermaria masculina especificamente para receber os 'espanholados'. Na enfermaria São Roque seriam isolados os doentes do próprio hospital e aqueles advindos de embarcações que tocavam o porto de Salvador. Segundo o relatório do serviço do Hospital Santa Izabel, ali ficaram internados 31 doentes de gripe, dos quais 28 receberam alta, e 3 faleceram. ${ }^{51}$ No Livro de registro de enterramentos do Campo Santo, o endereço do hospital foi registrado como o local de origem de muitos que foram sepultados nesse cemitério. ${ }^{52}$

O distrito da Sé, que figurou na estatística oficial com $23 \%$ dos óbitos por gripe ocorridos em Salvador, era uma área de grande densidade populacional. ${ }^{53}$ Apesar de ter a maior parte dos seus edifícios ocupada por negócios ou serviços, $58 \%$ dos prédios da região eram residenciais. Inquilinos de poucos recursos ocupavam $94 \%$ desses imóveis. Em alguns trechos, como no Pelourinho, famílias inteiras se espremiam em sobrelojas ou porões das casas comerciais, em "avenidas" ou em sobrados subdivididos. Ali se instalaram os artesãos, os que viviam de biscates e as prostitutas..$^{54}$ Os mendigos também transitavam pela Sé, prostrando-se nos átrios e portas das igrejas ou nas entradas das lojas, dos cafés e restaurantes da rua Chile, do Elevador Lacerda, do Plano Inclinado e paradas dos bondes, na esperança de arrancar alguma esmola aos transeuntes. ${ }^{55}$

Próximo dali, nos distritos de Santana e do Passo, o percentual de mortes atingiu, respectivamente, $14 \%$ e $4 \%$ do total de moradores. ${ }^{56}$ Nesses distritos, como na maioria, não havia um corte expressivo entre a camada média e a camada pobre da sociedade baiana. Em Santana, 88\% dos moradores não possuíam casa própria, vivendo em imóveis alugados. No pequeno distrito do Passo, espremido entre a Sé, Santo Antônio e Nazaré, $74 \%$ dos

49 CASTELLUCCI, op. cit., p. 40-41.

50 Em 1918, a Fábrica São Salvador, pertencente à Companhia União Fabril da Bahia, empregava 120 operários. A vila São Salvador foi construída em 1893 na região limítrofe entre os bairros de Nazaré e Brotas. Cf.: ANNUARIO..., op. cit., p. 277; CARDOSO, op. cit., p. 140.

51 SANTA CASA DA MISERICÓRDIA DA BAHIA. Diretoria do Hospital Santa Izabel. Relatório do Serviço do Hospital Santa Izabel durante o ano de 1918. 1919. p. 129-131.

52 SANTA CASA DA MISERICÓRDIA DA BAHIA. Livro de registro de enterramentos do Campo Santo. 7 dez. 1915 a 26 ago. 1923. p. 88-128.

53 Dados estatísticos referentes ao período de 27 de setembro a 31 de outubro de 1918, referentes a um total de 216 óbitos por gripe ou influenza ou por complicações da doença, publicados no jornal governista $O$ Democrata. Cf.: DIRECTORIA Geral de Saúde Pública da Bahia. Serviço de Estatística Demografo-Sanitária. O Democrata, Salvador, p. 2, 10 nov. 1918.

54 SOUZA, op. cit., p. 37-57; CASTELLUCCI, op. cit., p. 40; PINHEIRO, op. cit., p. 256-260.

55 LEITE, Rinaldo César Nascimento. E a Bahia civiliza-se... ideais de civilização e cenas de anticivilidade em um contexto de modernização urbana. Salvador, 1912-1916. 1996. Dissertação (Mestrado em História) Faculdade de Filosofia e Ciências Humanas, Universidade Federal da Bahia, Salvador, 1996. p. 135.

56 Dados estatísticos referentes ao período de 27 de setembro a 31 de outubro de 1918, referentes a um total de 216 óbitos por gripe ou influenza ou por complicações da doença, publicados no jornal governista $O$ Democrata. Cf.: DIRECTORIA Geral de Saúde Pública da Bahia. Serviço de Estatística Demografo-Sanitária. O Democrata, Salvador, p. 2, 10 nov. 1918. 
prédios ainda eram residenciais, $96 \%$ das pessoas eram inquilinos de poucos recursos financeiros, que viviam em condições semelhantes às dos moradores da Sé. Ali proliferavam casas de cômodo, sobrados subdivididos e casebres colados uns aos outros - imóveis de baixo aluguel, cujas condições nem sempre eram as mais recomendáveis pelos médicos e inspetores sanitários. ${ }^{57} \mathrm{Na}$ ladeira do Taboão agrupavam-se os indigentes, na esperança de receber uma esmola que Ihes remediasse a miséria. ${ }^{58}$

Juntos, os distritos da Conceição da Praia e do Pilar concentraram 23\% das mortes provocadas pela epidemia. ${ }^{59}$ Situados na Cidade Baixa, Conceição da Praia e Pilar constituíam-se, no século XIX, em reduto dos comerciantes, principalmente os de origem portuguesa. O distrito da Conceição da Praia situava-se em estreita faixa de terra que margeava o mar - ia da Gamboa à praça da Inglaterra, no Comércio. Na área do Comércio erguiam-se prédios de três ou quatro andares, construídos no século XIX para abrigar grandes casas de negócio, onde também residia a família, os funcionários, os escravos ou empregados domésticos e se mantinha um estoque de mercadorias. ${ }^{60}$ Progressivamente os negociantes e suas famílias foram se mudando para os bairros mais distantes, com melhor estrutura urbana, como a Vitória, ficando ali apenas os funcionários que não queriam ou não podiam se afastar do trabalho. ${ }^{61}$

A condição dos empregados em estabelecimentos comerciais não diferia muito da do operariado. O pagamento dos seus vencimentos tanto podia ser feito mediante uma quantia de dinheiro mensal, como o empregador poderia oferecer refeição e alojamento como parte da remuneração pelos serviços prestados. Contudo, nas duas situações o valor não era fixo e geralmente o caixeiro fazia retiradas mensais para prover minimamente sua subsistência, deixando o restante do salário sob a guarda do empregador. Havia um teto anual para tais retiradas e o patrão estimulava o empregado a sacar o mínimo possível, acenando-lhe com a possibilidade de um dia vir a galgar a posição de sócio no negócio. A realização dessa promessa era bastante remota e só se concretizava para uma minoria insignificante. A maioria dos caixeiros, principalmente aqueles empregados em casas comerciais de portugueses e espanhóis, morava precariamente no local de trabalho, onde, além das funções habituais, acumulava os serviços de guarda-livros, faxineiro e vigilante do negócio do patrão. ${ }^{62}$

Pequenas fábricas do ramo do vestuário também tinham a Conceição por endereço. ${ }^{63}$ O número de adoecimentos por gripe nas fábricas de Salvador foi grande. Variou de $100 \%$ a

57 CASTELLUCCI, op. cit., p. 40; PINHEIRO, op. cit., p. 256-260.

58 LEITE, op. cit., p. 135.

59 DIRECTORIA Geral de Saúde Pública da Bahia. Serviço de Estatística Demografo-Sanitária. O Democrata, Salvador, p. 2, 10 nov. 1918.

60 O negócio funcionava no térreo, a família residia no segundo pavimento, os últimos andares da edificação estavam reservados para as mercadorias, os empregados e/ou escravos. Cf.: PINHEIRO, op. cit., p. 193-194.

61 Idem, p. 256-260

62 SANTOS, op. cit., p. 56-57.

63 ANNUARIO ESTATÍSTICO DA BAHIA, 1923. Bahia: Diretoria do Serviço de Estatística do Estado da Bahia; Imprensa Oficial, 1924; REIS, Antonio Alexandre Borges dos (org). Almanak indicador comercial e administrativo do estado da Bahia. Bahia: Editores Reis \& Comp., v. 10, p. 175-282, 1919-1920. 
$80 \%$ do contingente de operários. Os estabelecimentos mais atingidos foram, principalmente, as fábricas de roupas, de acessórios do vestuário, de cigarros e de embalagens. ${ }^{64} \mathrm{Em}$ muitos desses espaços, a disseminação da doença era facilitada pela proximidade entre os funcionários, que trabalhavam muito próximos, lado a lado ou um em frente ao outro.

Naquela altura, a mão de obra feminina já havia sido absorvida pelo mercado formal de trabalho, tornando-se importante contingente, principalmente no setor fabril. ${ }^{65}$ As mulheres das classes mais desfavorecidas concorriam para o sustento próprio ou da família, atuando igualmente no mercado informal como lavadeiras, quituteiras, empregadas domésticas, bordadeiras, rendeiras, costureiras, chapeleiras, floristas, agricultoras, quitandeiras, feirantes etc. ${ }^{66}$ Transitavam continuamente pelas ruas da cidade, a cantar seus pregões, mulheres com seus balaios, gamelas e tabuleiros, vendendo produtos do artesanato doméstico, frutas, verduras, vísceras de gado, além de beiju, mingau, cuscuz, acarajé, cocada e outras iguarias da culinária baiana. ${ }^{67}$

Na Conceição da Praia, sobretudo em torno do Mercado Modelo, em cuja rampa atracavam os saveiros que traziam produtos oriundos das cercanias da cidade e do Recôncavo, se instalaram muitos vendedores ambulantes atraídos pela grande circulação de pessoas no local. Pelo mesmo motivo, era também um ponto estratégico de grande quantidade de mendicantes. Todavia, estes nem sempre conseguiam obter o mínimo para garantir a sua sobrevivência. Portanto, era frequente ocorrer naquela região a morte de um grande número de indigentes, abatidos pela fome ou por variadas doenças, disseminadas por pessoas de variadas origens, em trânsito ou aglomeradas naquele lugar. ${ }^{68}$

O distrito do Pilar figurou nas estatísticas com $18 \%$ das mortes ocorridas em Salvador. Situado na Cidade Baixa, na estreita faixa litorânea que ia do Cais Dourado ao Forte da Jequitaia, esse distrito abrigava o porto, os grandes estabelecimentos comerciais, as firmas de importação e exportação, os bancos, os trapiches, mercados, armazéns, depósitos etc. ${ }^{69}$ Ainda assim, aproximadamente $59 \%$ dos prédios dessa área eram residenciais e $92 \%$ estavam ocupados por inquilinos de poucas posses, instalados nas imediações do complexo comercial e infraestrutural que caracterizava essa parte da cidade. Nos antigos sobrados encortiçados agrupavam-se aqueles que buscavam trabalho como carregadores na zona portuária. ${ }^{70} \mathrm{O}$ índice de contaminação entre os portuários foi grande $-99 \%$ foram acometidos pela gripe. ${ }^{71}$ As desfavoráveis condições de trabalho e de sobrevivência, além do contato contínuo com

64 DIRECTORIA Geral de Saúde Pública. O Democrata, Salvador, p. 2, 6 nov. 1918.

65 SANTOS, op. cit., p. 50; CASTELLUCI op. cit., p. 28-31.

66 ALMEIDA, Maria Amélia Ferreira de. Feminismo na Bahia. 1930-1950. 1986. Dissertação (Mestrado em Ciências Sociais) - Faculdade de Filosofia e Ciências Humanas, Universidade Federal da Bahia, Salvador, 1986. p. 44; FERREIRA FILHO, Alberto Heráclito. Salvador das mulheres: condição feminina e cotidiano popular na Belle Époque imperfeita. 1994. Dissertação (Mestrado em História) - Faculdade de Filosofia e Ciências Humanas, Universidade Federal da Bahia, Salvador, 1994. p. 32-33; SANTOS, op. cit., p. 22-55.

67 SANTOS, op. cit., p. 27

68 LEITE, op. cit., p.130-136.

69 REIS, op. cit., p. 194.

70 CASTELLUCCI, op. cit., p. 40-41.

71 DIRECTORIA Geral de Saúde Pública. O Democrata, Salvador, p. 2, 6 nov. 1918. 
pessoas oriundas de lugares assolados pela epidemia, tornavam esses trabalhadores alvo fácil da doença.

As embarcações que atracavam ao movimentado porto de Salvador frequentemente traziam a bordo tripulantes e/ou passageiros infectados. Os doentes em estado grave eram encaminhados para o Isolamento de Monte Serrat. ${ }^{72} \mathrm{Na}$ coluna intitulada Medicina e Higiene, um colaborador do Jornal de Notícias afirmava que a invasão da epidemia de gripe constituía prova indiscutível de que a Bahia não dispunha de defesa marítima. Segundo o articulista, o governo federal se mostrava negligente com a Saúde do Porto, que se encontrava desaparelhada dos "meios necessários às suas atribuições e fins" - proteger o porto de Salvador da invasão de doenças exógenas. ${ }^{73}$ Outras notícias veiculadas em diferentes órgãos da imprensa demonstravam que a insatisfação com a atuação da União nesse quesito era geral. ${ }^{74}$

Igualmente situados na Cidade Baixa, os distritos dos Mares e da Penha, em conjunto, apresentaram $37 \%$ do total de mortes por gripe. ${ }^{75} \mathrm{O}$ distrito dos Mares figurou nas estatísticas oficiais com $14 \%$ de óbitos. No largo dos Mares situava-se a Fábrica Nossa Senhora da Conceição, com 850 operários. ${ }^{76}$ Ali estavam instaladas as fábricas de cigarros A. Guimarães \& Cia., com 170 operários, localizada na travessa dos Mares; a Leite \& Alves, com 500 operários, e a Martins Fernandes \& Cia., com aproximadamente 90 funcionários, ambas na Calçada do Bonfim..$^{77}$ Os operários dessas fábricas moravam nas imediações, o que thes facilitava o acesso e barateava ou eliminava os custos com transporte.

O distrito da Penha concentrou $23 \%$ de mortes em consequência da gripe ou de complicações dessa doença. ${ }^{78}$ Localizado na península de Itapagipe, englobava os atuais bairros da Ribeira, Bonfim, Monte Serrat, Massaranduba e Boa Viagem. O distrito abrigava o polo têxtil de Salvador: a Fábrica Boa Viagem, que empregava 1.400 operários, localizada na avenida Luiz Tarquínio; a Fábrica Bonfim, com 535 operários, no largo do Bonfim; a Fábrica Paraguaçu, com seus 520 operários, implantada no largo do Papagaio; a Fábrica São João, com 165 trabalhadores, instalada no porto dos Tainheiros; e a Fábrica Nossa Senhora da Penha, com 100 operários, na Ribeira. Além da indústria têxtil, a Penha contava com duas fábricas de calçados: a Gama \& Gama, que empregava 100 operários, e a Trocadero, com 120 operários, localizada na avenida Luiz Tarquínio. ${ }^{79}$

A Penha tinha a mais alta concentração de imóveis por proprietário registrada em Salvador, sinal de que a maior parte dos seus habitantes eram pessoas de baixa renda,

72 SOUZA, op. cit., p. 113-119.

73 MEDICINA E HIGIENE. Jornal de Notícias, Salvador, p. 2, 4 nov. 1918.

74 SOUZA, op. cit., p. 113-119.

75 DIRECTORIA Geral de Saúde Pública da Bahia. Serviço de Estatística Demografo-Sanitária. O Democrata, Salvador, p. 2, 10 nov. 1918.

76 ANNUARIO, op. cit.; REIS, op. cit., p. 281.

77 CASTELLUCCI, op. cit., p. 37.

78 DIRECTORIA Geral de Saúde Pública da Bahia. Serviço de Estatística Demografo-Sanitária. O Democrata, Salvador, p. 2, 10 nov. 1918.

79 ANNUARIO ESTATÍSTICO DA BAHIA, 1923. Bahia: Diretoria do Serviço de Estatística do Estado da Bahia; Imprensa Oficial, 1924; REIS, Antonio Alexandre Borges dos (org). Almanak indicador comercial e administrativo do estado da Bahia. Bahia: Editores Reis \& Comp., v. 10, p. 281, 1919-1920. 
que moravam de aluguel. ${ }^{80}$ Segundo o médico Américo D. Ferreira, inspetor sanitário desse distrito, como as fábricas vinham ampliando os seus quadros de pessoal, muitos habitantes de outros distritos haviam se deslocado para aquele local, a fim de estarem próximos ao local de trabalho. Naquela altura, apesar do lugar de destaque que a indústria têxtil ocupava no incipiente parque industrial da Bahia, seus operários estavam com os salários defasados diante do custo de vida observado na época. Os empregadores usavam os prejuízos derivados da alta dos preços dos insumos, da paralisação nas vendas e da desvalorização dos seus produtos como justificativa para não oferecer nenhum reajuste nos salários dos trabalhadores ${ }^{81}$ Esse argumento também era utilizado para explicar a paralisação total ou parcial da produção em algumas fábricas e a ampliação das horas de trabalho em outras, o que implicava em demissões ou maior exploração do trabalhador. ${ }^{82}$

Ferreira lamentava que a maioria do operariado, especialmente os operários das fábricas de tecidos, se visse "compelido pela necessidade a residir em prédios já [...] condenados", situados em becos e ruas de difícil acesso da Massaranduba e de outras localidades "reconhecidamente insalubres". ${ }^{33}$ Não à toa, segundo um articulista do jornal O Imparcial, a gripe "se aposentou" na região, visto que por ali "viviam em promiscuidade indivíduos de todas as espécies", "em cubículos esconsos" situados nos "fundos de umas casas". Corroborando o que dizia o médico, em 15 de outubro de 1918, nota veiculada na primeira página do 0 Imparcial informava que na Massaranduba o mal ia se propagando, de modo assustador - no curto período de 24 horas foram retirados da localidade seis cadáveres de indigentes.

Os moradores dos distritos de S. Pedro e Vitória foram os menos atingidos pela gripe $-2,8 \%$ dos óbitos ocorreram em São Pedro e 4,7\% na Vitória. ${ }^{84}$ Talvez porque ali, especialmente na Vitória, vivessem as camadas mais abastadas da população - pessoas bem nutridas, que habitavam em elegantes, iluminados e arejados solares, situados em avenida larga, pavimentada, iluminada e arborizada. Em São Pedro - freguesia próxima ao centro e valorizada pelas obras de modernização empreendidas por Seabra - residia parte da elite intelectual e social da cidade. Contudo, nesses bairros persistiam bolsões de pobreza, localizados nas áreas não reformadas, cujos habitantes prestavam algum tipo de serviço doméstico às vizinhas elites. Em São Pedro residiam pessoas oriundas da escravidão e outras vindas do campo em busca de ocupação na cidade. Na Vitória, as habitações proletárias concentravam-se em especial nas áreas do Garcia, Fazenda

80 CARDOSO, op. cit., p. 187; CASTELLUCCI, 2001, p. 40.

81 Segundo Castellucci, o ramo têxtil enfrentou uma crise de superprodução no segundo semestre de 1918 e até o primeiro trimestre de 1919 , devido ao cancelamento das encomendas anteriormente feitas pelo comércio atacadista, que também suspendeu todos os pedidos novos, alegando já dispor de um estoque incompatível com a sua capacidade de comercialização. Cf.: CASTELLUCCI, Aldrin A. Silva. Flutuações econômicas, crise política e greve geral na Bahia da Primeira República. Revista Brasileira de História, v. 25, n. 50, p. 131-166, 2005. Disponível em: http://www.scielo.br. Acesso em: 3 ago. 2007.

82 Idem, p. 136-137.

83 A Fábrica Boa Viagem havia construído uma vila com moradias, escola e biblioteca para os seus operários, mas era uma exceção à regra. FERREIRA, op. cit., 1921.

84 DIRECTORIA Geral de Saúde Pública da Bahia. Serviço de Estatística Demografo-Sanitária. O Democrata, Salvador, p. 2, 10 nov. 1918. 
Garcia, Federação e imediações do Porto da Barra, originariamente zona de moradia de pescadores. ${ }^{85}$

Pelo exposto até aqui, pode-se pensar que a gripe só atingia os pobres. Não é verdade. A doença não escolhia gênero, idade, condição socioeconômica, nem cor. Como para confirmar o assédio indiscriminado da "espanhola", o jornal O Imparcial estampou na primeira página a notícia que o senador Luiz Vianna havia contraído a gripe. A nota informava que as sessões do Congresso se encontravam esvaziadas devido ao grande número de deputados e senadores acometidos pela gripe ${ }^{86} \mathrm{Em}$ finais de outubro, notícia publicada no jornal $A$ Tarde informava que o "futuro presidente da República" Rodrigues Alves e alguns membros de sua família haviam contraído a gripe, o que causou comoção nacional. ${ }^{87}$ Rodrigues Alves morreu antes mesmo que pudesse assumir o governo. Em semelhantes notícias ficava implícito que a epidemia representava ameaça também para as elites, visto que não poupava nem as figuras importantes do cenário político local e nacional. Os jornais da época ora reforçavam o caráter igualitário da doença, ora o contradiziam. O discurso tecido em torno da democracia da doença contribuía para sensibilizar e conscientizar as elites em relação aos problemas sanitários revelados pelo mal.

É fato que a doença acometia a todos, contudo, a igualdade dos indivíduos diante da doença era relativa - alguns eram mais vulneráveis à sua invasão. No período de pico da epidemia - da última quinzena de setembro à última quinzena de outubro - observou-se uma elevação nas taxas da mortalidade geral em Salvador. Segundo Gonçalo Moniz, tal ocorreu porque doenças "fortemente debilitantes", como a gripe, agravavam "estados mórbidos crônicos anteriores", aumentando o número de mortes por outras enfermidades. Esse médico chamava a atenção para a "influência agravante da gripe" sobre doenças ou "afecções latentes", como a tuberculose pulmonar, as cardiopatias, as nefropatias etc., "[...] de que já sofriam muitos dos acometidos do mal epidêmico, e cuja existência é assim abreviada". ${ }^{88}$

É difícil precisar, portanto, quantos morreram e quem eram as vítimas da "espanhola". Além dos que morreram devido ao agravamento de doenças preexistentes, havia a questão da subnotificação da causa mortis, dificultada pela variabilidade dos sintomas da doença e das complicações por ela provocadas - distúrbios nervosos, graves complicações pleuropulmonares, digestivas, renais e/ou cardiovasculares -, que acabavam figurando nos atestados de óbitos em lugar da gripe propriamente dita. Reportagem veiculada no jornal $O$ Imparcial informava que "raros eram os casos de gripe atestados", ainda que fosse "comum ouvir-se, das próprias famílias das vítimas, a declaração de que os seus entes sucumbiram à gripe, à influenza". ${ }^{89}$ É provável que as famílias optassem por mascarar a causa da morte

85 PINHEIRO, op. cit., p. 194.

86 O SENADOR Luiz Vianna de gripe. O Imparcial, Salvador, p. 1, 22 out. 1918.

87 CONS. RODRIGUES ALVES. A Tarde, Salvador, p. 2, 28 out. 1918.

88 MONIZ, op. cit., p. 415.

89 CRESCE A MORTANDADE! Cifras eloquentes sobre o estado sanitário da cidade. E, na classe média, as cifras são alarmantes! O Imparcial, Salvador, p. 1, 11 out. 1918. 
devido às restrições impostas e aos problemas relativos a óbitos por doença infectocontagiosa a legislação vigente determinava que os familiares não podiam velar o corpo, nem acompanhar o féretro, nem assistir ao sepultamento, a casa tinha que ser expurgada e os objetos de uso pessoal do enfermo, queimados. ${ }^{90}$

Quem eram, afinal, as vítimas da "espanhola"? Qual a condição socioeconômica da maioria? Os mais abastados, que contavam com a assistência do médico de família à cabeceira do leito, tinham a opção de suprimir informações, burlar a recomendação de notificação da doença, ou os indigentes atendidos pelo serviço público de saúde? Quantos morriam à míngua, nas vias públicas ou nos domicílios e hospitais? Morriam mais velhos e crianças do que jovens? Morriam mais homens que mulheres? Qual a cor dos que mais morriam?

Toma-se por base o relatório do Serviço de Estatística Demografo-Sanitária, publicado no jornal O Democrata, referente ao intervalo de tempo entre 27 de setembro e 31 de outubro de 1918, período de pico da epidemia, como amostragem das vítimas da doença. Segundo esses registros, num universo de 216 mortos, 58\% das vítimas eram homens, pouco mais de $96 \%$ eram brasileiros, mais de $72 \%$ eram solteiros, mais de $63 \%$ tinham entre 20 e 60 anos de idade, pouco mais de $37 \%$ teve a atividade profissional registrada, $87 \%$ morreu em casa. ${ }^{91}$ O Serviço de Verificação de Óbitos não registrou a cor das vítimas. Porém, os dados publicados nesse jornal, referente a períodos subsequentes a esse, confrontados por informações obtidas em outra fonte, revelam que a maioria dos óbitos registrados foram de "pardos", que constituíam da maioria da população de Salvador. ${ }^{92}$ Portanto, morreram mais homens de cor "parda", solteiros, jovens, trabalhadores pobres ou de profissão ignorada, cuja jornada extenuante de trabalho e as precárias condições de vida, certamente, favoreceram o desenvolvimento da doença com resultado funesto. Não podemos deixar de considerar que muitos desses soteropolitanos não procuraram logo o médico, não só por falta de recursos, mas porque a princípio se acreditava ser aquela uma doença benigna, facilmente curável com repouso e mezinhas caseiras; sem falar naqueles que, embrutecidos pela miséria absoluta, não sabiam a quem recorrer e nem recebiam nenhum tipo de assistência, morrendo à míngua, sem o conhecimento das autoridades.

Já havia transcorrido quase um mês desde que a gripe irrompera em Salvador e, nesse período, além de nomear uma comissão de médicos para estudar o evento, nenhuma outra medida foi tomada por parte da Diretoria Geral da Saúde Pública da Bahia para controlar a doença e assistir os gripados. A gripe se espalhou pela cidade e muitas foram as pessoas que

90 Para saber mais, confiram em: SOUZA, op. cit., p. 37-89.

91 DIRECTORIA Geral de Saúde Pública da Bahia. Serviço de Estatística Demografo-Sanitária. O Democrata, Salvador, p. 2, 10 nov. 1918.

92 DIRECTORIA Geral de Saúde Pública da Bahia. Mortalidade de gripe. O Democrata, Salvador, p. 2, 17 nov. 1918; DIRECTORIA Geral de Saúde Pública da Bahia. Serviço de Estatística Demografo-Sanitária. 0 Democrata, Salvador, p. 1, 1 dez. 1918; SANTA CASA DA MISERICÓRDIA DA BAHIA. Livro de registro de enterramentos do Campo Santo. 7 dez. 1915 a 26 ago. 1923, p. 88-128. 
morreram sem que o serviço público tomasse conhecimento ou mesmo lhes prestasse algum tipo de assistência.

Finalmente, em 23 de outubro de 1918, o governador Antônio Ferrão Moniz de Aragão resolveu oferecer socorros médicos e farmacêuticos aos indigentes. Para tal, a DGSPB dividiu a cidade em seis zonas sanitárias e instituiu um médico comissionado para cada uma delas, a fim de atender os doentes em domicílio. Farmácias foram credenciadas para servir de apoio aos médicos e aviar as receitas e fornecer gratuitamente os remédios aos reconhecidamente indigentes. Na semana de 27 de outubro a 2 de novembro, 215 pessoas acometidas de gripe foram atendidas pelo serviço especial de assistência médica e farmacêutica instituído pela DGSPB, o que apresenta média de 30,7 casos por dia. ${ }^{93}$ Em pouco mais de 90 dias, tempo de duração da epidemia em Salvador, a gripe espanhola infectou mais de $40 \%$ da população e vitimou 386 pessoas.

\section{Considerações finais}

QUANDO A GRIPE ESPANHOLAaportou em Salvador, o movimento inicial das autoridades públicas foi negar a existência de uma epidemia de gripe em Salvador. As epidemias exacerbam as tensões entre grupos que disputam o poder, desafiam a capacidade das autoridades públicas de administrar bem a crise, evidenciam os limites da ciência e da medicina e revelam as vulnerabilidades e desigualdades da sociedade. É comum que haja a eleição de culpados pelo surgimento e disseminação da doença. As facções políticas promoveram acalorado debate na imprensa em busca de culpados - a oposição buscou responsabilizar o governo pela invasão e disseminação da doença e o grupo governista acusou os oposicionistas de supervalorizarem o evento em causa própria.

Os médicos procuraram estabelecer um diagnóstico, em meio às dissonâncias existentes no meio científico e acadêmico mundial. Cientes da grande visibilidade que a imprensa dava ao evento, especialmente os jornais que faziam oposição ao governo, os profissionais que integravam o quadro do serviço público de saúde procuraram demonstrar segurança, competência e agilidade para estabelecer o diagnóstico, recomendar medidas profiláticas e terapêuticas adequadas. Eles sabiam que não havia um remédio específico para a doença. Não havia, também, tempo hábil para desenvolver uma vacina. A epidemia se disseminava em velocidade inversamente proporcional ao tempo necessário para atender aos protocolos requeridos pela ciência. Assim, eles consideraram a gripe como um problema sanitário, defendendo a adoção de medidas de saúde pública para conter o mal que se disseminava com inesperada virulência na Bahia, contribuindo para o agravamento das suas mazelas.

$\overline{93}$ DIRECTORIA Geral de Saúde Pública da Bahia. O Democrata, Salvador, p. 1, 10 nov. 1918. 
Em um período de crise na habitação e grande especulação imobiliária, as pessoas de poucos recursos se aglomeravam em casas de cômodo, em velhos sobrados encortiçados, casas geminadas e todo tipo de imóvel de baixo aluguel que proliferavam nos bairros operários e nos distritos do antigo centro de Salvador. Esse tipo de moradia, que favorecia o convívio próximo de vários indivíduos em espaços exíguos e mal arejados, contribuiu para a rápida propagação da gripe, que facilmente se espalhou pelos bairros mais pobres da cidade.

Embora a gripe não escolhesse suas vítimas, mas, segundo os médicos, havia maior probabilidade de óbito entre aqueles cujo organismo se encontrava enfraquecido - fosse por doenças preexistentes ou crônicas, fosse em razão das precárias condições materiais de existência. A ideia da "democracia da doença" veiculada pela imprensa foi importante para mobilizar os diferentes segmentos da sociedade em torno das medidas de controle da epidemia. Porém, ainda que atingisse a todos de forma indiferenciada, a maioria das vítimas era constituída por trabalhadores e por aqueles grupos denominados pelo serviço público como indigentes. Isso se justifica quando se observa a qualidade de vida da maior parte da população baiana no ano de 1918 - desalojada pelas reformas urbanas, aglomerada em lugares insalubres, alquebrada pelo desemprego, pela carestia, pela fome e por doenças endêmicas e epidêmicas precedentes. Nessas condições, é compreensível que não oferecessem resistência à gripe espanhola, constituindo-se na maioria das vítimas da doença.

Recebido em 18/06//2020

Aprovado em 04/08/2020 